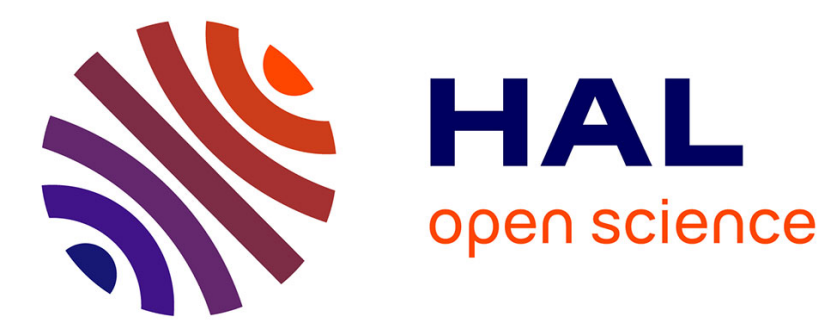

\title{
Genetic diversity of in ticks and small ruminants in The Gambia determined by restriction fragment profile analysis
}

Bonto Faburay, Frans Jongejan, Amar Taoufik, Ansumana Ceesay, Dirk Geysen

\section{To cite this version:}

Bonto Faburay, Frans Jongejan, Amar Taoufik, Ansumana Ceesay, Dirk Geysen. Genetic diversity of in ticks and small ruminants in The Gambia determined by restriction fragment profile analysis. Veterinary Microbiology, 2007, 126 (1-3), pp.189. 10.1016/j.vetmic.2007.06.010 . hal-00532278

\section{HAL Id: hal-00532278 https://hal.science/hal-00532278}

Submitted on 4 Nov 2010

HAL is a multi-disciplinary open access archive for the deposit and dissemination of scientific research documents, whether they are published or not. The documents may come from teaching and research institutions in France or abroad, or from public or private research centers.
L'archive ouverte pluridisciplinaire HAL, est destinée au dépôt et à la diffusion de documents scientifiques de niveau recherche, publiés ou non, émanant des établissements d'enseignement et de recherche français ou étrangers, des laboratoires publics ou privés. 


\section{Accepted Manuscript}

Title: Genetic diversity of Ehrlichia ruminantium in Amblyomma variegatum ticks and small ruminants in The Gambia determined by restriction fragment profile analysis

Authors: Bonto Faburay, Frans Jongejan, Amar Taoufik, Ansumana Ceesay, Dirk Geysen

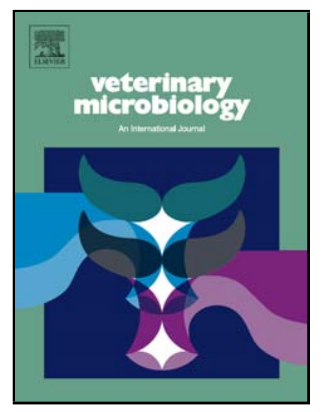

PII: S0378-1135(07)00309-4

DOI: doi:10.1016/j.vetmic.2007.06.010

Reference: VETMIC 3732

To appear in: $\quad$ VETMIC

Received date: 24-3-2007

Revised date: 29-5-2007

Accepted date: $\quad$ 14-6-2007

Please cite this article as: Faburay, B., Jongejan, F., Taoufik, A., Ceesay, A., Geysen, D., Genetic diversity of Ehrlichia ruminantium in Amblyomma variegatum ticks and small ruminants in The Gambia determined by restriction fragment profile analysis, Veterinary Microbiology (2007), doi:10.1016/j.vetmic.2007.06.010

This is a PDF file of an unedited manuscript that has been accepted for publication. As a service to our customers we are providing this early version of the manuscript. The manuscript will undergo copyediting, typesetting, and review of the resulting proof before it is published in its final form. Please note that during the production process errors may be discovered which could affect the content, and all legal disclaimers that apply to the journal pertain. 
1 Genetic diversity of Ehrlichia ruminantium in Amblyomma

2 variegatum ticks and small ruminants in The Gambia determined by

3

4

5

6

7

8

9

10

11

12

13

14

15

16

17

18

19

20

21

22

23

24

25

26

27

28 restriction fragment profile analysis

\author{
Bonto Faburay $^{13^{*}}$, Frans Jonge ja n ${ }^{3,4}$, Amar Taoufik ${ }^{3}$, Ansumana Ceesay ${ }^{1}$, and \\ Dirk Geysen ${ }^{2}$
}

${ }^{1}$ International Trypanotolerance Centre, PMB 14, Banjul, The Gambia

${ }^{2}$ Prince Leopold Institute of Tropical Medicine, Nationalestraat 155, B-2000 Antwerp, Belgium

${ }^{3}$ Utrecht Centre for Tick-borne Diseases, Faculty of Veterinary Medicine, Utrecht University, Yalelaan 1, 3584CL Utrecht, The Netherlands

${ }^{4}$ Department of Veterinary Tropical Diseases, Faculty of Veterinary Science, University of Pretoria, Private Bag X04, Onderstepoort 0110, South Africa

\section{Veterinary Microbiology}

*Corresponding author; Mailing address: Utrecht Centre for Tick-borne Diseases,

Faculty of Veterinary Medicine, Utrecht University, Yalelaan 1, 3584CL Utrecht, The

Netherlands; Tel.: +31 302531114; fax: +31 302546723

E-mail address: b.fabureh1@,vet.uu.nl 
Abstract

Understanding genetic diversity of Ehrlichia ruminantium in host and vector populations is an important prerequisite to controlling heartwater by vaccination in traditional livestock systems in sub-Saharan Africa. We carried out a study in two phases: i) evaluating the usefulness of the PCR-RFLP assay based on the map 1 coding sequence of E. ruminantium as a discriminatory tool to characterise genetic diversity, ii) applying the technique to field samples from A. variegatum ticks and small ruminants to characterise genotypic diversity of the organism in 3 main agroecological zones of The Gambia, Sudano-Guinean (SG), Western SudanoSahelian (WSS) and Eastern Sudano-Sahelian (ESS). Restriction fragment length polymorphisms were observed among different strains of E. ruminantium supporting the usefulness of the PCR-RFLP technique for studying genetic diversity of the organism. Restriction enzyme mapl profile analysis indicated the presence in The Gambia of multiple genotypes (at least 11) of E. ruminantium with sites in the WSS and SG zones showing comparatively high number of diverse genotypes. Profiles similar to the Kerr Seringe genotype (DQ333230) showed the highest distribution frequency, being present at sites in all 3 agroecological zones, thereby making the strain a suitable candidate for further characterisation in cross-protection studies. An additional 3 genotypes showed relatively high distribution frequency and were present in all 3 zones making them equally important for isolation and subsequent characterisation. The study demonstrated the occurrence of mixed infections with $E$. ruminantium genotypes in ruminants and ticks.

Keywords: Ehrlichia ruminantium; map 1; Restriction Fragment Length Polymorphism; genetic diversity; genotypes; The Gambia 


\section{Introduction}

Heartwater is a rickettsial disease of domestic and wild ruminants caused by Ehrlichia (formerly Cowdria) ruminantium (Dumler et al., 2001). The organism is transmitted by ticks of the genus Amblyomma; the major vector in West Africa is A. variegatum, which is distributed in most parts of sub-Saharan Africa and on some islands in the Caribbean (Walker and Olwage, 1987). Hearwater represents a sign ificant obstacle to improvement of livestock production in the tropics and subtropics with mortality rates ranging from $20-90 \%$ in susceptible animals (Uilenberg, 1983). Small ruminants are particularly at risk from the disease.

Different genotypes of E. ruminantium (Allsopp et al., 1997) were found using PCR and sequencing of the V1 loop (Neefs et al., 1993) small-subunit ribosomal RNA gene and random amplified polymorphic DNA and southern blotting (Perez et al., 1997); and stocks with differing immunogenicity exist in the field (Du Plessis et al., 1989). In The Gambia, frequent cases of mortality due to heartwater has been observed in indigenous small ruminants upon translocation from the eastern part of the country to the western part and potential antigenic diversity between different stocks of $E$. ruminantium in the different locations was considered a possible cause (Faburay et al., 2005). Over the past five decades, efforts to control heartwater through development of vaccines have been considerably hampered by the presence of a wide diversity of E. ruminantium stocks in the field, which demonstrated phenotypic differences. It is therefore essential to have information on the variety and distribution of stocks within a target area prior to initiating or planning any large-scale vaccination or disease control programmes. At present there is no simple and reliable method for the molecular typing of different E. ruminantium stocks (Jongejan and Bekker, 1999). 
82 The mapl gene of E. ruminantium represents an ideal target for genotypic 83 characterisation (Allsopp et al., 1999) as it shows a high degree of sequence 84 polymorphisms between isolates (Allsopp et al., 2001; Reddy et al., 1996), does not vary during host-tick passages (D. Martinez, unpublished) and is conserved in all $E$. ruminantium isolates from different geographic regions examined so far (Allsopp et al., 2001; Barbet et al., 1994; Van Vliet et al., 1994). In the present study, we used polymerase chain reaction-restriction fragment length polymorphism (PCR-RFLP) technique (Geysen et al., 2003) on the mapl gene to characterise genetic diversity of E. ruminantium in ticks and small ruminants in The Gambia. This study was carried out in two phases: i) evaluating the usefulness of a PCR-RFLP assay of the map 1 coding sequence of E. ruminantium to distinguish between different isolates; ii) characterisation of genetic diversity of E. ruminantium in the tick vector and small ruminant hosts at selected sites in the three principal agroecological zones of The Gambia.

\section{Materials and Methods}

\section{Study sites}

Sudano-Guinean zone (SG)

Sampling sites $\left(13^{\circ} 43^{\prime} \mathrm{N}, 16^{\circ} 72^{\prime} \mathrm{W}\right)$ in the Sudano-Guinean zone were located within the 900 and $1210 \mathrm{~mm}$ of rainfall isohyets. Maximum daily temperatures range from $26^{\circ}$ to $32^{\circ} \mathrm{C}$ (Climatological Unit, Dept. of Water Resources, The Gambia). The vegetation is savannah-woodland or woodland in certain areas, with Acacia spp., Cordia spp. and Elaeis guineensis predominating lowland ecologies. In some areas around the coast, the vegetation is characterized by humid tropical forest vegetation.

\section{Western Sudano-Sahelian zone (WSS)}


109 Sampling sites $\left(13^{\circ} 20^{\prime} \mathrm{N}, 16^{\circ} 01^{\prime} \mathrm{W}\right)$ in the Western Sudano-Sahelian zone received an

110 average of $800 \mathrm{~mm}$ of rainfall isohyets with maximum daily temperatures ranging

111 from 28 to $38^{\circ} \mathrm{C}$. The vegetation is composed of degraded savannah woodland

112 interspersed with natural unimproved grasslands dominated by Andropogon gayanus

113 and Meriscus spp., and also with trees and farmland. The lowland tree vegetation

114 consists principally of low and high mangroves.

115

116 Eastern Sudano-Sahelian zone (ESS)

117 Annual precipitation at the sampling sites $\left(13^{\circ} 27^{\prime} \mathrm{W}, 14^{\circ} 40^{\prime} \mathrm{N}\right)$ in the Eastern

118 Sudano-Sahelian zone averages $700 \mathrm{~mm}$ of rainfall isohyets with maximum

119 temperatures ranging from $30^{\circ}$ to $40^{\circ} \mathrm{C}$. The vegetation is mainly open savannah

120 interspersed with trees, grasses and arable farmland. Towards the river, riparian

121 woodland, including Mitragyna inermis and Acacia seyal, with scattered Adansonia

122 digitata are interspersed with rice fields.

123

124

125

126 Blood was collected in EDTA from extensively managed sheep and goats. The blood

127 was introduced into plain microhaematocrit capillary tubes and centrifuged for 5

128 minutes to separate the buffycoat. The microtube was cut just beneath the buffycoat.

129 The latter was applied to Whatman ${ }^{\circledR}$ filter paper No. 3 or 4 by bringing the tube in

130 contact with the filter paper to allow absorption. The filter paper was allowed to dry at

131 room temperature and then stored at $-20^{\circ} \mathrm{C}$ until used. DNA was extracted by the

132 Modified Plowe extraction method using saponin-chelex (Geysen et al., 2003). Tick

133 samples were preserved in $70 \%$ ethanol and DNA was extracted from them

134 individually ( $n=145$ ticks) or pooled in batches $2-5$ ticks ( $n=512$ ticks) using the

135 DNeasy $^{\mathrm{TM}}$ Tissue kit for isolation of genomic DNA from insects (Qiagen, Westburg, 
136 Leusden, The Netherlands). Genomic DNA from 16 reference strains of $E$.

137 ruminantium (Table 1) was extracted from blood, tick or culture stabilates using the

138 Qiagen $^{\circledR}$ Blood Fluid Spin Protocol. The DNA extracts were stored at $-20^{\circ} \mathrm{C}$ until

139 used.

140

$141 \quad$ Nested map1 PCR

142 All primers were designed using the Clustal alignment of ten different E. ruminantium

143 mapl sequences from GenBank ${ }^{\mathrm{TM}}$ as described in (Faburay et al., 2007) and various

144 computer DNA software programmes including PC-rare (Griffais et al., 1991),

145 Rightprimer $^{\mathrm{TM}}$ version M1.2.5 (Biodisk, USA) and PrimerPremier (Biosoft

146 international, USA). Briefly, amplification of the map 1 gene was carried out using the

147 following primers:

148

149

150

151

152

153

154

155

156

157

158

159

160

- external forward primer (ERF3) 5'-CCAGCAGGTAGTGTTTACATTAGCGCA-3'

- external reverse (ERR1) 5'-CAAACCTTCCTCCAATTTCTAT ACC-3'

- internal reverse (ERR3) 5'-GGCAAACATCAAGTGTTGCTGATGC-3'

Thus the external forward primer (ERF3) in the first round PCR was also maintained as the internal forward primer for the second round amplification. PCR amplification was carried out in a $25 \mu \mathrm{l}$ volume containing $5 \mu \mathrm{l}$ DNA sample, $50 \mathrm{mM} \mathrm{KCl}, 10 \mathrm{mM}$ Tris- $\mathrm{HCl}(\mathrm{pH} 8.3), 1.5 \mathrm{mM} \mathrm{MgCl}_{2}, 200$ pmol of each dNTP, 40 pmol of each primer and $0.4 \mathrm{U}$ of Taq polymerase. After a DNA denaturing step at $94^{\circ} \mathrm{C}$ for $3 \mathrm{~min}$, the first round of amplification (simple PCR) using ERF3 and ERR1 was carried out using the following conditions: 40 cycles of 1 min denaturation at $92{ }^{\circ} \mathrm{C}, 1 \mathrm{~min} 30 \mathrm{sec}$ annealing at $60{ }^{\circ} \mathrm{C}$ and $2 \mathrm{~min}$ elongation at $72^{\circ} \mathrm{C}$ and a final extension of $10 \mathrm{~min}$ at $72^{\circ} \mathrm{C}$. A $0.5 \mu 1$ aliquot of PCR product from the first round amplification was transferred as template to a second round of PCR (nested PCR) at $84^{\circ} \mathrm{C}$ (hot start 
161 principle) with ERF3 and ERR3 primers consisting of 25 cycles of the same PCR

162 conditions as in the first round except the annealing temperature which was set at

$16358^{\circ} \mathrm{C}$. In each PCR run, positive and negative controls were included. Positive 164 controls were derived from E. ruminantium (Kerr Seringe) DNA obtained from cell

165 culture derived organisms and negative controls were reagent blank samples without 166 DNA. The PCR amplified a $720-738$ bp fragment of the map 1 gene of $E$. 167 ruminantium. Amplification products from all PCR assays were visualised in $1.5 \%$ 168 agarose gels after staining with ethid ium bromide.

169

171

172

174

\section{Sensitivity of nested map1 PCR}

Ten-fold serial dilutions of culture-derived purified E. ruminantium DNA of Kerr Serigne isolate were made to test the sensitivity of the nested mapl PCR in a previous study (Faburay et al., 2007). Also, DNA derived from A. variegatum ticks $(n=145)$ collected randomly from traditionally managed cattle and DNA from blood samples of traditionally managed small ruminants $(n=150)$ were tested in the simple and nested PCR to evaluate the sensitivity of the assay.

\section{Restriction Fragment Length Polymorphism (RFLP) analysis}

PCR amplification products obtained from nested mapl PCR of field (from ticks and small ruminants) and reference strains of E. ruminantium were subjected to restriction enzyme analysis with the restriction enzyme, Alu1 as recommended by the manufacturer (New England Biolabs $\left.{ }^{\circledR}\right)$. Four microlitres of the digested sample was mixed with $2 \mu \mathrm{l}$ of loading buffer and loaded onto a $10 \%$ polyacrylamide gel. A 100 bp ladder was included to determine the fragment size. DNA fragments were separated by horizontal electrophoresis in $1 \mathrm{x}$ TBE buffer at $100 \mathrm{~V}$ for $2 \mathrm{~h}: 40 \mathrm{~min}$. The gel was subjected to silver or SYBR ${ }^{\circ}$ green (Cambrex Bio science Rockland Inc.) staining according to the manufacturer's instructions and visualised under ultraviolet 
187 illumination. The gels were photographed using a digital camera (NikonE4500, Nikon

188 Corp.) fitted with a green filter (for SYBR green-stained gels).

189

190

191

192

193

194

195

196

197

198

\section{Temporal stability of map 1}

To ass ess the reliability of the results of the RFLP, the stability of mapl over time was examined in vivo and in vitro. In vivo evaluation involved a goat artificially infected with E. ruminantium (Kerr Seringe) and treated with oxytetracycline following manifestation of clinical symptoms. The an imal consequently became a carrier, which was confirmed by examining genomic DNA extracts from whole blood by nested map 1 PCR as described above. Thereafter, sequential DNA samples were collected at weekly intervals and subsequently analysed in the PCR-RFLP assay. In the in vitro evaluation, we examined the mapl profile stability of bovine umbilical endothelial cell culture-derived E. ruminan tium of the Senegal stock at passage levels 1, 15, 30, 72 and 81 .

\section{Genetic diversity studies}

The aim of this part of the study was to determine the extent of genotypic diversity of E. ruminantium in The Gambia. Genomic DNA was extracted from adult $A$. variegatum ticks (male and female) and small ruminant (sheep and goat) whole-blood samples collected at selected sites/villages representative of the three major agroecological zones of the country (SG, WSS, ESS) described above. Table 2 summarizes the number of cattle herds sampled for ticks, A. variegatum ticks collected, and small ruminants sampled for the study. Overall, 657 partially engorged or unfed (flat females) ticks were collected in fifteen villages from selected cattle herds in the three main study areas (Table 2). These herds were located in geographically widely separated villages, and in most places, the animals travelled 
214 long distances daily in search of forage and were therefore potentially exposed to

215 challenge with E. ruminantium from different areas. In addition, we made 150

216 genomic DNA extracts from whole blood collected from extensively managed small

217 ruminants in the same villages as indicated in the sampling frame (Table 2). All

218 samples were tested using the nested mapl PCR and samples that gave specific

219 positive amplicons were subsequen tly typed by RFLP analysis.

220

221

222

223

224
Gene sequencing and analysis of sequence identity

Two field samples, one from a tick and the other from a sheep, gave mapl PCR products mixed profiles. The mapl PCR products from these samples and also from E. ruminantium (Kerr Seringe) were cloned into pGEM-T Easy Vector Systems (Promega, Madison, USA). The resulting recombinant plasmids were transformed into Escherichia coli $\mathrm{DH} 5 \alpha$ and plated out on X-gal/IPTG plates. Positive transformants (colourless) were selected and confirmed by PCR. Confirmed transformants were subsequently cultured overnight at $37{ }^{\circ} \mathrm{C}$ in LB-Ampicillin medium and the plasmids were isolated using the GFX PCR DNA and Gel Band purification kit (Amersham Biosciences, Sweden). The purified plasmids were sent to a commercial company (BaseClear, Leiden, The Netherlands or VIB Genetic Service Facility, Antwerp, Belgium) for sequencing. Overall, six map 1 clones (er80/1, er80/2, er80/8, er80/10, L4306/8, L4306/3) were obtained from the field samples and together with the Kerr Seringe stock, were subsequently sequenced. These sequences were aligned with mapl sequences of thirteen reference strains (Table 1) obtained from GenBank, using the ClustalW method. Sequence distances or percentage identity between different strains or stocks of E. ruminantium was determined using MegAlign 4.00 (DNASTAR Inc.). 
240

241 General Linear Model (GLM) procedure (SAS ${ }^{\circledR}$ statistical programme) was used to 242 determine the level of significance of differences in genotypic diversity of $E$. 243 ruminantium in the three agroecological zones. Mean frequencies of the various 244 profiles and the significance of differences between the frequencies of the various 245 profiles were determined by one-way analysis of variance (ANOVA) with 246 Bonferroni-corrected P-value (Stata ${ }^{\circledR}$ statistical programme). Overall frequencies of 247 the various mapl genotypes detected in the study were determined using Excel 248 programme (Microsoft® Corp.).

\section{Results}

251 Sensitivity of nested map $1 P C R$

252 Serial 10-fold dilutions of purified DNA showed a 100-fold increase of the sensitivity 253 in the nested mapl PCR compared to the simple map1 PCR. In conjunction with real254 time PCR using mapl-1 primers (Postigo et al., 2007), the nested technique was 255 shown to have a detection threshold of 1 E. ruminantum organism in a sample 256 (Faburay et al., 2007). In ticks, the simple PCR technique detected an infection rate of $2575.2 \%$, whereas the nested technique detected $11 \%(n=145)$. Similarly in small 258 ruminants, the infection rate detected by simple PCR was $4 \%$, whereas it was $10.6 \%$ 259 by nested PCR $(n=150)$.

260

261

262 The PCR-RFLP protocol was validated for the sixteen E. ruminantium strains (Table

263 1). In the PCR assay, the primers amplified specific amplicons from all the strains 264 except Kümm (data not shown). The RFLP assay was able to distinguish between the 265 different strains of E. ruminantium (Figure 1). Based on similarities between the 266 individual map 1 restriction profiles, the isolates were grouped into six clusters: i) Kerr 
267 Seringe 1, Sankat 430 ii) Kiswani, Um Banein iii) Pokoase 417, Senegal iv) Gardel,

268 Lutale v) Kwanyanga, Nigeria (Ifé), vi) Burkina Faso, Welgevonden, Sao Tomé,

269 Bela Vista, Nonile. Restriction profiles of Um Banein, Nigeria (Ifé), Bela Vista,

270 Lutale and Nonile are not shown. Analys is of the respective mapl restriction profiles

271 did not show any geographical clustering among the different isolates. Also, the

272 restriction profile of map 1 gene of E. ruminantium in vivo (Kerr Seringe stock), in the

273 4-month observation period, and in vitro (Senegal stock), did not manifest any change

274 suggesting temporal stability of the target gene in infected ruminant hosts.

275 Additionally, map1 gene was reported not to vary during host-tick passages (D.

276 Martinez, unpublished).

277

278 Genetic diversity of $\mathrm{E}$. ruminantium in The Gambia

279 Restriction enzyme analysis of mapl coding sequences of E. ruminantium in field

280 samples from $A$. variegatum ticks and small ruminants revealed 11 different profiles

281 (Figure 2; Table 3). Figure 3 shows the overall frequency of the different map 1 282 genotypes detected in the three agroecological zones of The Gambia, whereas 283 statistical analysis of the mean frequencies of the various profiles is shown in Table 4.

284 Frequencies of the various genotypes observed in the study were significantly 285 different $(\mathrm{P}=0.0257)$. Profile 1 showed the highest overall frequency of $25.8 \%$ 286 (Table 3), mean and maximum frequency (Table 4) and was present at sites in all 3 287 zones with the frequency highest in the SG zone (Table 3). Profile 6 showed the 288 second highest overall frequency $(15.1 \%)$ followed by profiles 3 and 11, the latter 289 two showing the same frequency (14\%). These profiles were similarly present in all 3 290 agroecological zones. Comparison of differences in the frequencies between profile 1 291 and the rest of the profiles ranged from the borderline of significance $(\mathrm{P}=0.060)$ to 292 not significant $(P=1.000)($ Table 4$)$. Differences in genotypic diversity observed at 
293 sites in the three agroecological zones were statistically not significant $(\mathrm{P}=0.182)$.

294 Sites in the SG and WSS zones showed a diversity of 8 and 9 different profiles 295 respectively; whereas sites in the ESS zone showed 5 different profiles (Table 3).

296 Profiles 2 and 5 were only seen in the SG zone, whereas profile profile 8, 9 and 10 297 were detected only in the WSS zone. The profiles of a number of mapl genotypes 298 detected in this study were identical to the restriction profiles of some of the reference 299 strains of E. ruminantium distributed throughout heartwater-endemic regions in sub300 Saharan Africa and the Caribbean (Figure 1). For example, profile 1 was identical to 301 Sankat and Kerr Seringe, profile 2 to Kiswani and Um Banein, profile 3 to Gardel, 302 Lutale, profile 4 to Kwanyanga and Nigeria (Ifé), profile 5 to Senegal and Pokoase, 303 and profile 10 to Welgevonden, Nonile, Burkina Faso, Sao Tomé and Bela Vista.

304 As mentioned above, the PCR amplified a 720-738 bp fragment of the map 1 gene of 305 E. ruminantium. Thus the sum of restriction bands, counted against a 100bp scale, of 306 any RFLP profile of $1400 \mathrm{bp}$ and above was considered to be mixed. One sample 307 derived from a tick (in Kerr Seringe) and one from a sheep (in Keneba) showed mixed 308 RFLP profiles (data not shown); the map 1 PCR products derived from these samples 309 were subsequently cloned and sequenced as described previously. Four mapl clones 310 (er80/1, er80/10, er80/2, er80/8,) were derived from the tick sample suggesting mixed 311 infection with 4 E. ruminantium genotypes, and the sample from the sheep showed 2 312 mapl clones (er/L4306/3, er/L4306/8) suggesting co-infection with 2 E. ruminantium 313 genotypes. The mapl coding sequences of Kerr Seringe strain and the six clones, 314 er80/1, er80/10, er80/2, er80/8, er/L4306/3 and er/L4306/8, derived from the field 315 samples, were submitted to GenBank and assigned accession nos. DQ333230, 316 EF627980, EF627981, EF627982, EF627983, EF627984 and EF627985, respectively. 
319 Analysis of percentage identity of map 1 sequences

320 Analysis of percentage identity of mapl coding sequences derived from the clones

321 and E. ruminantium reference strains showed no evidence of geographic clustering.

322 Despite being geographically distant, the mapl coding sequence of Kerr Seringe 1

323 (Gambia) showed high percentage identity (98.6\%) to Sankat 430 (Ghana), whereas

324 Pokoase (Ghana) showed genetic relatedness to Senegal (99 \%). Despite originating

325 from sites less than 30km apart (Bell-Sakyi et al., 2004), the two Ghanaian isolates

326 (Sankat 430 and Pokoase 417) were relatively genetically distant showing a percent

327 homology of $92.6 \%$. Similarly, Kerr Seringe and Senegal strains, although

328 originating from closely related geographical areas with similar bioclimatic

329 environment, were found to be genetically distant $(90.4 \%)$. Of the four clones

330 derived from the tick, 3 (EF627982, EF627983, EF627981) showed high percentage

331 identity to the Senegal/Pokoase 417 strains suggesting close genetic similarity to these

332 strains (98.6 - $98.7 \%$ identity); EF627980 showed high percentage identity (98.8 \%)

333 to Nonile. Of the 2 clones derived from the sheep co-infection, EF627984 showed

$33494.2 \%$ identity to Kerr Seringe/Sankat 430 strains and EF627985 was identical to

$335(97.8-99.2 \%)$ to the Gardel/Lutale strains.

336

337 Discussion

338 The use of restriction endonuclease digestion of target genes (Brindley et al., 1993;

339 Gasser et al., 1994; Geysen et al., 2003) or bacterial chromosomes (De Villiers et al.,

340 2000), with infrequently cutting restriction endonucleases, has produced restriction

341 profiles that give reliable fingerprints for strain- and species-specific identification.

342 We used the PCR-RFLP targeting the polymorphic mapl gene to characterise

343 potential genetic diversity of E. ruminantum in ticks and small ruminants at selected 
344 sites in different agroecological zones (SG, WSS, and ESS) of The Gambia. The

345 nested PCR amplification approach considerably increased the sensitivity of the as say

346 resulting in an improved rate of specific amplification of target E. ruminantium DNA

347 in ticks and notably carrier small ruminants for subsequent analysis by RFLP. Using

348 AluI restriction endonuclease, we were able to distinguish amongst West African and

349 Southern African isolates (Figure 1). The technique distinguished between the four

350 West African isolates examined, Kerr Seringe, Senegal, Sankat 430 and Pokoase 417.

351 In contrast, De Villiers et al. (2000) used SmaI and KspI restriction enzymes in

352 separate digestions on whole genomic DNA and were unable to distinguish between 353 the three West African isolates, Senegal, Sankat 430 and Pokoase 417. The reason for 354 their failure to distinguish between the E. ruminantium isolates may be due to 355 digestion of whole genomic DNA instead of a specific amplified gene target, map 1, as 356 in the present study.

358 Comparison of the various restriction profiles detected in tick and animal samples 359 originating from the 3 agroecological zones showed remarkable diversity. Overall, 11 360 map1 genotypes were detected in the study (Figure 2; Table 3). Frequencies of the 361 various profiles in the study areas were significantly different $(P=0.0257)$. Profile \#

362 1, which was identical to the Gambian Kerr Seringe strain, appeared to be the most 363 widely distributed, with the highest overall, mean and maximum frequency (Figure 3; 364 Table 3, Table 4), and was present in all three study zones of the country (Table 3). 365 Two and three mapl genotypes were identified only in the SG and WSS zones 366 (towards the coastal area) respectively (Table 3), supporting the hypothesis that 367 susceptible livestock translocated from sites in the far eastern part of the country 368 (ESS) to the western part towards the coast are at greater risk of exposure to challenge 
369

370

371

372

373

374

375

with genotypically different stocks of E. ruminantium, which could potentially differ immunologically thereby resulting in mortalities due to lack of cross-protection. In a recent vaccination experiment involving sheep, the attenuated Senegal isolate which conferred full protection against the local Kerr Seringe isolate on-station was able to confer only $75 \%(n=12)$ protection in a field trial in a limited geographical area in the SG zone (authors' unpublished results). The three case-fatalities were caused by an E. ruminantium stock found to be genotypically different from the Kerr Seringe strain confirmed by RFLP analysis of brain samples (authors' results, in preparation for publication). Frequent cases of mortality due to heartwater have been observed in small ruminants upon translocation from the eastern part of the country to coastal Gambia (SG and westerly part of WSS zone). Although lack of immunity indicated by significantly low seroprevalence among small ruminant populations in the eas tern part of the country has been reported to contribute to these mortalities (Faburay et al., 2005), antigenic disparities between stocks (Jongejan et al., 1988, 1991), which may reflect, to some extent, genotypic differences among E. ruminantium stocks in the different ecological localities, could also be an important cause. In Burkina Faso, the lack of protective immunity confirmed in cross-protection studies in considerably limited geographic area was attributed to diversity ( 5 mapl genotypes detected in the area) between strains (Martinez et al., 2004).

Differences in genotypic diversity of profiles between the three agroecological zones was statistically not significant $(\mathrm{P}=0.182)$. However, sites in the WSS and SG zones showed comparatively high number of diverse mapl genotypes (Table 3 ). This was attributed, principally, to the effect of introduction of E. ruminantium carrier animals from other parts of the country and beyond its borders. For example, one of the study 
394 sites in the WSS zone is host to an ITC station for an Open-nucleus Ruminant Pure

395 Breeding Programme characterised by regular introduction of breeding stock from

396 diverse geographical areas, while the largest centre for trade in ruminant livestock in 397 the country is located in the SG zone, which encompasses the coastal area. 398 Furthermore, profiles identical to that of the Kerr Seringe strain, isolated from a goat 399 in the SG zone, were also identified at sites in the WSS and ESS zones. This led us to 400 postulate that the Kerr Seringe strain may have been introduced from the eastern part 401 of the country following the route of livestock trade from east to west in The Gambia. 402

403 Analysis of the map1 restriction profile of E. ruminantium reference strains did not 404 reveal any geographical clustering. However, the clustering based on restriction 405 profile similarity was able to show diversity within West African as well Southern 406 African isolates indicating the usefulness of the RFLP method as a tool for 407 characterising genotypic diversity of E. ruminantium in the field. Although mapl was 408 shown to be a stable molecular marker for identification of E. ruminantium strains, 409 clusters generated by the RFLP technique did not correlate with cross protection 410 amongst strains of E. ruminantium supporting previous reports that mapl gene 411 identity between strains may not be a predictor of cross-immunity (Martinez et al., 412 2004). For instance, the Senegal isolate belonged to a different cluster from Kerr 413 Seringe. The attenuated strain of the former, however, provided complete protection 414 in sheep against lethal needle challenge using the Kerr Seringe isolate (unpublished 415 results).

417 In conclusion, the use of nested PCR in conjunction with RFLP proved to be a reliable 418 tool to characterise genetic diversity of E. ruminantium in the field. This study 
419 showed that multiple genotypes of E. ruminantium exist in the field and specifically in

420 The Gambia, which indicates the likelihood of a similar level of antigenic diversity 421 and therefore constitutes a major reason for heartwater vaccine failures. This suggests

422 the need for additional E. ruminantium strain isolation and characterisation especially 423 in cross-protection trials. The fact that the RFLP profile identical to the Kerr Seringe 424 isolate showed the highest frequency and was present in all 3 agroecological zones of 425 the country makes this strain a prime candidate for further evaluation in cross426 immunity studies. In addition to the Kerr Seringe strain, three other genotypes showed 427 significant frequency distribution and should also be considered important candidates 428 for isolation and subsequent characterisation. In general, the information derived from 429 this study should contribute to the design and development of appropriate control 430 measures (vaccination) and strategies against heartwater in The Gambia.

\section{Acknowledgement}

433 This work was supported by The European Development Fund, Service Contract No.

434 REG/6061/006, Rothamsted International (UK), Epigenevac project under contract 435 number no. INCO-CT-2005-003713 and ICTTD-2 concerted action project under 436 contract no. ICA4T-2000-30006, through the INCO-DEV programme of the European

437 Commission, the Utrecht Scholarship Programme of Utrecht University, The

438 International Foundation for Science in Sweden in partnersh ip with COMSTECH.

439 The authors are grateful to the field staff of ITC and the Department of Livestock

440 Services, The Gambia, for their support in field sampling. We appreciate the

441 assistance of Dr. Reginald De Deken, Dr. Cornelis Bekker, Lieve Vermeiren and

442 Jacob De Witte. We are most grateful to Dr. Lesley Bell-Sakyi for the critical and

443 insightful comments. Bonto Faburay holds a Rothamsted International African

444 Fellowship Award. 


\section{References}

Allsopp, M.E.T.P., Hattingh, C.M., Vogel, S.W., Allsopp., B.A., 1999, Evaluation of 16S, map 1 and pCS20 probes for the detection of Cowdria and Ehrlichia species. Epidemiol. Infect. 122, 323-328.

Allsopp, M.T., Dorfling, C.M., Milliard, J.C., Bensaid, A., Haydon, D.T., Van Heerden, H., Allsopp, B.A., 2001, Ehrichia ruminantium major antigenic protein gene (map1) variants are not geographically constrained and show no evidence of having evolved under positive selection pressure. J. Clin. Microbiol. 39, 4200-4203.

Allsopp, M.T.E.P., Visser, E.S., Du Plessis, J.L., Vogel, S.W., Allsopp, B.A., 1997, Different organisms associated with heartwater as shown by analysis of $16 \mathrm{~S}$ ribosomal RNA gene sequences. Vet. Parasitol. 71, 283-300.

Barbet, A.F., Semu, S.M., Chigagure, N., Kelly, P.J., Jongejan, F., Mahan, S.M., 1994, Size variation of the major immunodominant protein of Cowdria ruminantium. Clin. Diagn. Lab. Immunol. 1, 744-746.

Bekker, C.P.J., Vink, D., Lopes Pereira, C.M., Wapenaar, W., Langa, A., Jongejan, F., 2001, Heartwater (Cowdria ruminantium infection) as a cause of postrestcoking mortality of goats in Mozambique. Clin. Diagn. Lab. Immunol. 8, 843-846.

Bell-Sakyi, L., Koney, E.B.M., Dogbey, O., Walker, A.R., 2004, Ehrlichia ruminantium seroprevalence in domestic ruminants in Ghana. I. Longitudinal survey in the Greater Accra Region. Vet. Microbiol. 100, 175-188.

Bell-Sakyi, L., Koney, E.B.M., Dogbey, O., Abbam, J.A., Aning, K.G., 1997, Isolation and in vitro cultivation in Ghana of Cowdria ruminantium, the causative agent of heartwater. In Proceedings of the W.A.C.V.A/G.V.M.A. Conference, Koney, E.B.M. and Aning, K.G. (eds), Ministry of Food and Agriculture, Accra, pp46-51.

Brindley, P.J., Gazzineli, R.T., Denkers, E.Y., Davis, S.W., Dubey, J.P., Belfort Jr., R., Martins, M.C., Silvera, C., Jamra, L., Waters, A.P., Sher, A., 1993, Differentiation of Toxoplasma gondii from closely related coccidian by riboprint analysis and a surface antigen gene polymerase chain reaction. Am. J. Trop. Med. Hyg. 48, 447-456. 
478

479

480

481

482

483

484

485

486

487

488

489

490

491

492

493

494

495

496

497

498

499

500

501

502

503

504

505

506

507

508

509

510

511

De Villiers, E.P., Brayton, K.A., Zweygarth, E., Allsopp, B.A., 2000, Macrorestriction fragment profiles reveal genetic variation of Cowdria ruminantium isolates. J. Clin. Microbiol. 38, 1967-1970.

Du Plessis, J.L., Van Gas, L., Olivier, J.A., Bezuidenhout, J.D., 1989, The heterogenicity of Cowdria ruminantium stocks: Cross immunity and serology in sheep and pathogenicity to mice. Onderstepoort J. Vet. Res. 56, 195-201.

Du Plessis, J.L., 1985, A method for determining the Cowdria ruminantium rate of Amblyomma hebraeum: effects in mice infected with tick homogenates. Onderstepoort J. Vet. Res. 52, 55-61.

Du Plessis, J.L., Kumm, N.A.L., 1971, The passage of Cowdria ruminantium in mice. J. S. Afric. Vet. Med. Assoc. 42, 217-221.

Dumler, J.S., Barbet, A.F., Bekker, C.P.J., Dasch, G.A., Palmer, G.H., Ray, S.C., Rikihisa, Y., Rurangirwa, F.R., 2001, Reorganisation of genera in the families Rickettsiaceae and Anaplasmataceae in the order Rickettsiales: unification of some species of Ehrlichia and Ehrlichia with Neorickettsia, description of six new species combinations and designation of Ehrlichia equi and 'HGE agent' as subjective synonymous of Ehrlichia phagocytophila. Int. J. Syst. Evol. Microbiol. 51, 2145-2165.

Faburay, B., Geysen, D., Munstermann, S., Taoufik, A., Postigo, M., Jongejan, F., 2007, Molecular detection of Ehrlichia ruminantium infection in Amblyomma variegatum ticks in The Gambia. Exp. Appl. Acarol. DOI 10. 1007/s10493-

Faburay, B., Munstermann, S., Geysen, D., Bell-Sakyi, L., Ceesay, A., Bodaan, C., Jongejan, F., 2005, Point seroprevalence survey of Ehrlichia ruminantium infection in small ruminants in The Gambia. Clin. Diagn. Lab. Immunol. 12, 508-512.

Gasser, R.B., Chilton, N.B., Hoste, H., Stevenson, L.A., 1994, Species identification of trichostrongyle nematodes by PCR-linked RFLP. Int. J. Parasitol. 24, 291293.

Geysen, D., Delespaux, V., Geerts, S., 2003, PCR-RFLP using Ssu-rDNA amplification as an easy method for species-specific diagnosis of Trypanosoma species in cattle. Vet. Parasitol. 110, 171-180.

Griffais, R., Andre, P.M., Thibon, M., 1991, K-tuple frequency in the human genome and polymerase chain reaction. Nucleic Acids Res. 19, 3887-3891. 
512 Ilemobade, A.A., Blotkamp, J., 1976, Preliminary observations on the use of the

513

514

515

516

517

518

519

520

521

522

523

524

525

526

527

528

529

530

531

532

533

534

535

536

537

538

539

540

541

542

543

544

545

capillary flocculation test for the diagnosis of heartwater. Res. Vet. Sci. 21, 370-372.

Jongejan, F., Bekker, C.P.J., 1999, Cowdria ruminantium: recent developments in diagnostic methods, molecular characterization and vaccines. 373-386.

Jongejan, F., Thielemans, M.J.C., Briere, C., Uilenberg, G., 1991, Antigenic diversity of Cowdria ruminantium isolates determined by cross-immunity. Res. Vet. Sci. 51, 24-28.

Jongejan, F., Uilenberg, G., Franssen, F.F.J., Gueye, A., Nieuwenhuijs, J., 1988, Antigenic differences between stocks of Cowdria ruminantium. Res. Vet. Sci. 44, 186-189.

Jongejan, F., Morzaria, S.P., Omer, A.S., Hashim, M.A., 1984, Isolation and transmission of heartwater (Cowdria ruminantium infection) in Blue Nile Province. Sud. Vet. Res. Commun. 8, 141-145.

Kocan, K.M., Morzaria, S.P., Voigt, W.P., Kiarie, J., Irvin, A.D., 1987, Demonstration of colonies of Cowdria ruminantium in midgut epithelial cells Amblyomma variegatum. Am. J. Vet. Res. 48, 356-360.

MacKenzie, P.K.I., McHardy, N., 1984, The culture of Cowdria ruminantium in mice: Significance in respect of the epidemiology and control of heartwater. Prev. Vet. Med. 2, 227-237.

MacKenzie, P.K.I., Van Rooyen, R.E., 1981, The isolation and culture of Cowdria ruminantium in albino mice. Proceedings of an International Congress on Tick Biology and Control, Rhodes University, Grahams town, pp47-52.

Martinez, D., Vachiery, N., Starchurski, F., Kandassamy, Y., Raliniaina, M., Aprelon, R., Gueye, A., 2004, Nested PCR for detection and genotyping of Ehrlichia ruminantium: use in genetic diversity analysis. Ann. N. Y. Acad. Sci. 1026, 106-113.

Neefs, J.M., van de Peer, Y., de Rijk, P., Chapell, S., de Wachter, R., 1993, Compilation of small ribosomal subunit RNA structures. Nucleic Acids Res. 21, 3025-3049.

Perez, J.M., Martinez, D., Debus, A., Sheikboudou, C., Bensaid, A., 1997, Detection of genomic polymorphisms among isolates of the intracellular bacterium Cowdria ruminantium by random amplified polymorphic DNA and southern blotting. FEMS Microbiology Letters 1, 73-79. 
547 Postigo, M., Taoufik, A., L.Bell-Sakyi, Vries, E.D., Morrison, W.I., Jongejan, F., 548 2007, Differential expression of the major antigenic protein 1 multigene family of Ehrlichia ruminantium in ticks and in vitro cultures. Vet. Microbiol. doi:10.16/j.vetmic.2007.01.019.

Reddy, G.R., Sulsona, C.R., Harrison, R.H., Mahan, S.M., Burridge M.J., Barbet, 552 from Cowdria ruminantium isolates from different geographical areas. Clin. Diagn. Lab. Immunol. 154, 73-79.

Uilenberg, G., Camus, E., Barre, N., 1985, A strain of Cowdria ruminantium isolated in Guadeloupe (French West Indies). Rev. Elev. Méd. vét. Pays trop. 38, 3442.

Uilenberg, G., 1983, Heartwater (Cowdria ruminantium infection): Current status. Adv. Vet. Sci. Comp. Med. 27, 427-480.

Uilenberg, G., Corten, J.J., Dwinger, R.H., 1982, Heartwater (Cowdria ruminantium infection) on Sao Tome. Vet. Q. 4, 106-107.

Van Vliet, A.H.M., Jongejan, F., Van Kleef, M., Van Der Zeijst, B.A.M., 1994, Molecular cloning, sequence analysis, and expression of the gene encoding the immunodominant 32-kilodalton protein of Cowdria ruminantium. Infect. Immun. 62, 1451-1456.

569 
570

571

572

573

574

575

576

577

578

579

580

581

582

583

584

585

586

587

588

589

590

591

592

593

594

595

\section{Legends}

\section{Tables}

Table 1.E. ruminantium reference strains tested in the PCR-RFLP assay

Table 2. Sampling frame showing number of cattle herds, A. variegatum ticks and small ruminants sampled in villages in the three agroecological zones (AEZ) of The Gambia

Table 3. Outcome of RFLP restriction profile analysis of mapl from A. variegatum ticks and small ruminants in different agroecological zones (AEZ) of The Gambia

Table 4. Statistical analysis of mean frequencies of the various map1 RFLP profiles from small ruminants and $A$. variegatum ticks

\section{$\underline{\text { Figure Legends }}$}

Figure 1. RFLP of mapl gene of E. ruminantium reference strains showing profile diversity and the various clusters $(1=$ Kerr Seringe 1, $2=$ Burkina Faso, $3=$ Sankat 430, $4=$ Pokoase 417, $5=$ Kiswani, $6=$ Welgevonden, $7=$ Senegal, $8=$ Gardel, $9=$ Sao Tome, $10=$ Kwanyanga, $\mathrm{M}=100 \mathrm{bp}$ marker

Figure 2. RFLP of mapl showing the diversity of E. ruminantium profiles detected at various sites in The Gambia (profiles Nos. 1 to 11 ), $M=100 \mathrm{bp}$ marker

Figure 3. Overall frequency of the various mapl genotypes of E. ruminantium at various sites detected in the study 
Table 1.E. ruminantium reference strains tested in the PCR-RFLP assay

\begin{tabular}{llll}
\hline $\begin{array}{l}\text { E.ruminantium } \\
\text { strain }\end{array}$ & Geographic origin & $\begin{array}{l}\text { Source of } \\
\text { material }\end{array}$ & Reference \\
\hline Kerr Seringe1 & The Gambia & Culture & Faburay et al., 2005 \\
Senegal & Senegal & Culture & Jongejan et al., 1988 \\
Welgevonden & South Africa & Culture & Du Plessis, 1985 \\
Nonile & South Africa & Blood & Mac Kenzie \& Mc Hardy, 1984 \\
Kwanyanga & South Africa & Blood & MacKenzie \& Van Rooyen, 1981 \\
Burkina Faso & Burkina Faso & Ticks & Jongejan et al., 1995 unpublished \\
Lutale & Zambia & Blood & Jongejan et al., 1988 \\
Um Banein & Sudan & Blood & Jongejan et al., 1984 \\
Gardel & Guadeloupe & Culture & Uilenberg et al., 1985 \\
Kiswani & Kenya & Blood & Koc an et al., 1987 \\
Pokoase 417 & Ghana & Culture & Bell-Sakyi et al., 1997 \\
Sankat 430 & Ghana & Blood & Bell-Sakyi et al., 1997 \\
Nigeria (Ifé) & Nigeria & Blood & Illemobade, 1976 \\
Kümm & South Africa & Blood & Du Plessis \& Kümm, 1971 \\
Bela vista & Mozambique & Blood & Bekkeret al., 2001 \\
Sao Tomé & Sao Tomé & Blood & Uilenberg et al., 1982 \\
\hline
\end{tabular}


Table 2. Sampling frame showing number of cattle herds, $A$. variegatum ticks and small ruminants sampled in villages in the three agroecological zones (AEZ) of The Gambia

\begin{tabular}{|c|c|c|c|c|c|}
\hline $\begin{array}{l}\text { AEZ } \\
\text { sa mpled }\end{array}$ & No. of ca & rds sampled for tic ks & No. of ticks sampled & No. of small & ruminant \\
\hline Sudano-Guinean & $\begin{array}{l}\text { Kerr Seringe } \\
\text { Giboro kuta } \\
\text { Tumani Tenda } \\
\text { Mandinaba } \\
\text { Berefet/Somita }\end{array}$ & $\begin{array}{l}1 \\
2 \\
2 \\
1 \\
3\end{array}$ & $\begin{array}{l}40 \\
42 \\
50 \\
38 \\
55\end{array}$ & $\begin{array}{c}10 \\
8 \\
10 \\
10 \\
12\end{array}$ & \\
\hline $\begin{array}{l}\text { Western } \\
\text { Sudano-Sahelian }\end{array}$ & $\begin{array}{l}\text { Keneba } \\
\text { Burong } \\
\text { Kollikunda } \\
\text { Mbappa Ba } \\
\text { Mbappa Mariga }\end{array}$ & $\begin{array}{l}1 \\
1 \\
1 \\
2 \\
2\end{array}$ & $\begin{array}{l}46 \\
50 \\
40 \\
35 \\
30\end{array}$ & $\begin{array}{l}10 \\
10 \\
10 \\
10 \\
10\end{array}$ & \\
\hline $\begin{array}{l}\text { Eastern } \\
\text { Sudano-Sahelian }\end{array}$ & $\begin{array}{l}\text { Yorro Beri Kunda } \\
\text { Sare Sofie } \\
\text { MamutFana } \\
\text { Jimballa Kerr Chendu } \\
\text { Kulkullay } \\
\text { Sare Demba Torro }\end{array}$ & $\begin{array}{l}1 \\
1 \\
1 \\
2 \\
3 \\
2\end{array}$ & $\begin{array}{l}40 \\
25 \\
25 \\
42 \\
50 \\
50\end{array}$ & $\begin{array}{l}10 \\
10 \\
- \\
10 \\
10 \\
10\end{array}$ & \\
\hline Total & & 26 & 657 & 150 & \\
\hline
\end{tabular}


Table 3. Outcome of RFLP restriction profile analysis of mapl from $A$. variegatum tic ks and small ruminants in different agroecological zones (AEZ)

\begin{tabular}{|c|c|c|c|c|}
\hline \multirow{2}{*}{ Profile no. } & \multirow{2}{*}{$\begin{array}{l}\text { Frequency } \\
(\%)\end{array}$} & \multicolumn{3}{|c|}{ No. of profiles per agroecological zone } \\
\hline & & Sudano-Guinean & Western Sudano-Sahelian & Eastern Sudano-Sahelian \\
\hline 1 & 25.8 & 14 & 6 & 4 \\
\hline 2 & 2.2 & 2 & - & - \\
\hline 3 & 14.0 & 5 & 4 & 4 \\
\hline 4 & 10.0 & 6 & 3 & - \\
\hline 5 & 4.3 & 4 & - & - \\
\hline 6 & 15.1 & 7 & 2 & 5 \\
\hline 7 & 8.6 & 1 & 1 & 6 \\
\hline 8 & 2.2 & - & 2 & - \\
\hline 9 & 3.2 & - & 3 & - \\
\hline 10 & 1.1 & - & 1 & - \\
\hline 11 & 14.0 & 3 & 7 & 3 \\
\hline \multicolumn{2}{|c|}{ Total number of profiles per AEZ } & 8 & 9 & 5 \\
\hline
\end{tabular}


Table 4. Statistical analys is of mean frequencies of the various map1 RFLP profiles from small ruminants and $A$. variegatum ticks

\begin{tabular}{ccccc}
\hline Profile no. & Mean freque ncy \pm SD & Minimum frequency & Maximum frequency & Bonferroni-correc ted P-value $^{\mathbf{a}}$ \\
\hline 1 & & 4 & 14 & 0.089 \\
2 & $8.00 \pm 5.29$ & 0 & 2 & 1.000 \\
3 & $0.67 \pm 1.15$ & 4 & 5 & 1.000 \\
4 & $4.33 \pm 0.58$ & 0 & 6 & 0.194 \\
5 & $3.00 \pm 3.00$ & 0 & 4 & 1.000 \\
6 & $1.33 \pm 2.31$ & 2 & 7 & 0.871 \\
7 & $4.67 \pm 2.52$ & 1 & 6 & 0.089 \\
8 & $2.67 \pm 2.89$ & 0 & 2 & 0.131 \\
9 & $0.67 \pm 1.15$ & 0 & 3 & 0.060 \\
10 & $1.00 \pm 1.73$ & 0 & 1 & 1.000
\end{tabular}

${ }^{\mathrm{a}} P$ values depict comparison of differences between the frequency of profile 1 and individual frequencies of the various profiles; $P$ value of 0.05 or less is significant; 
$\underline{\text { Figure } 1}$

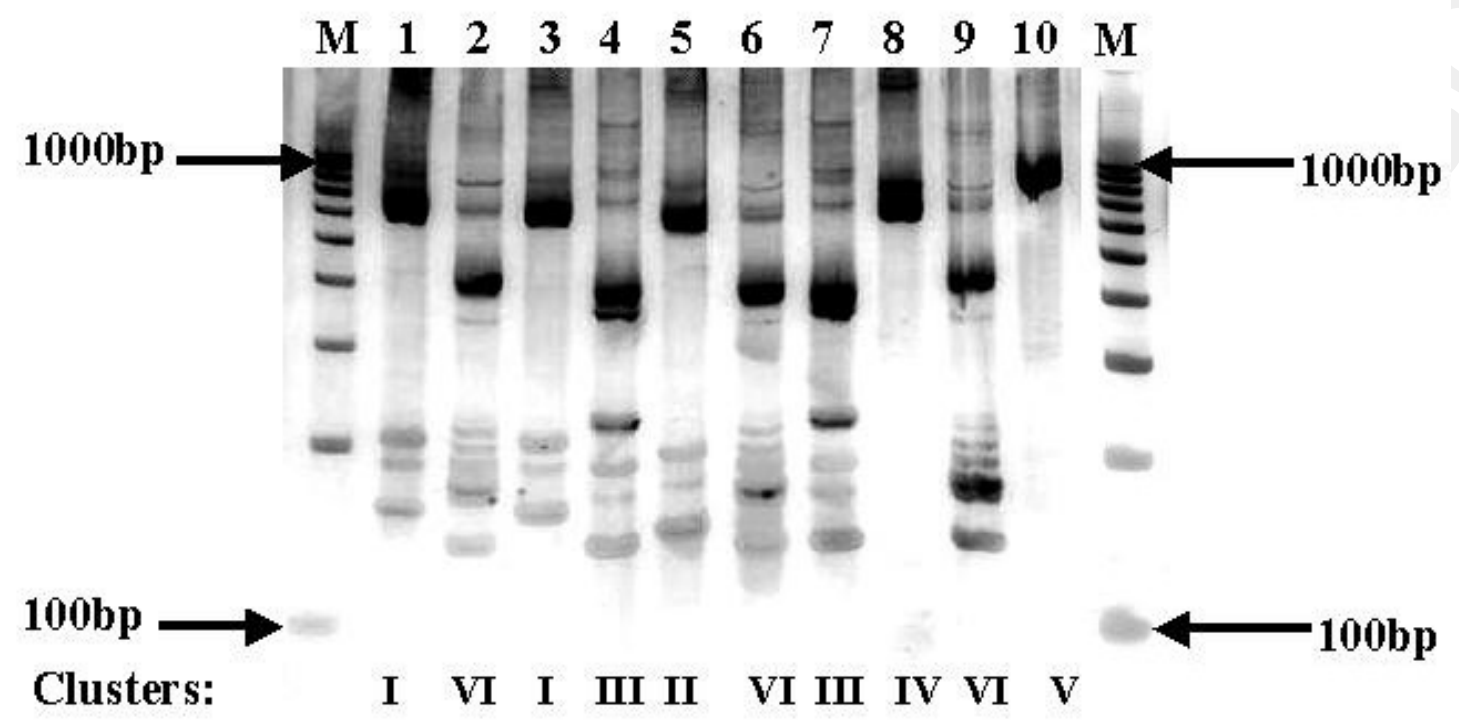


$\underline{\text { Figure } 2}$

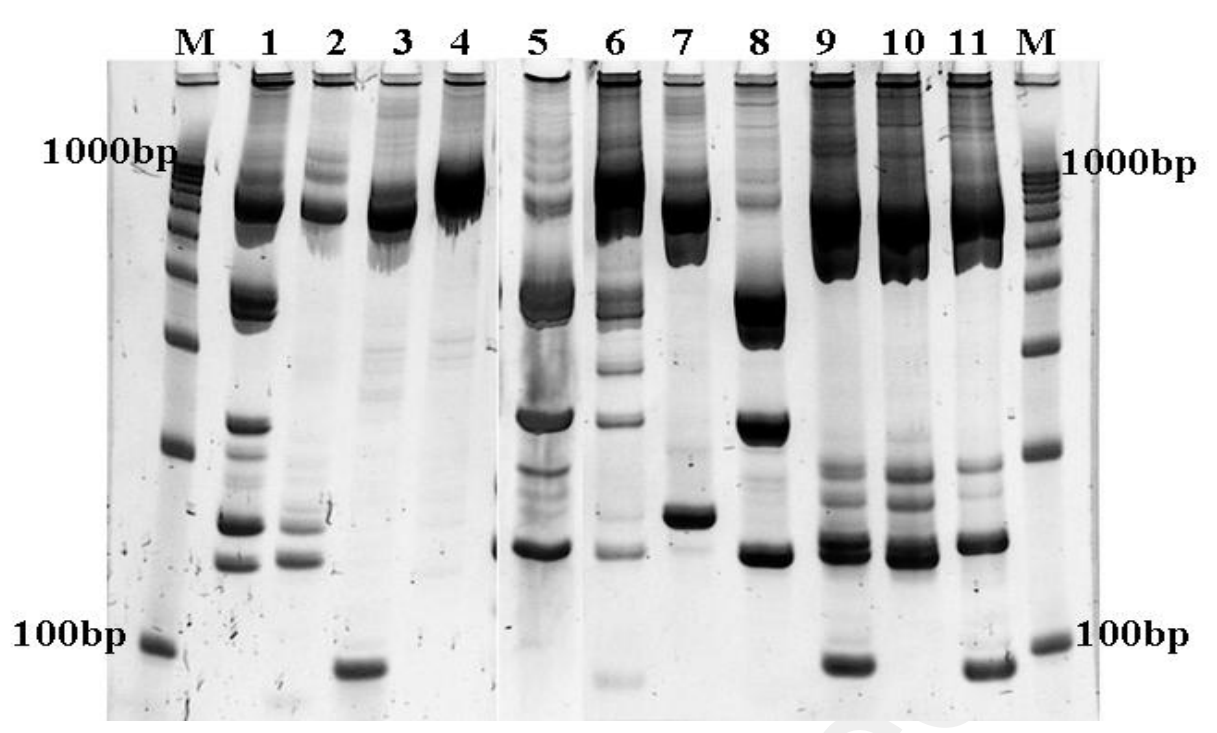


Figure 3

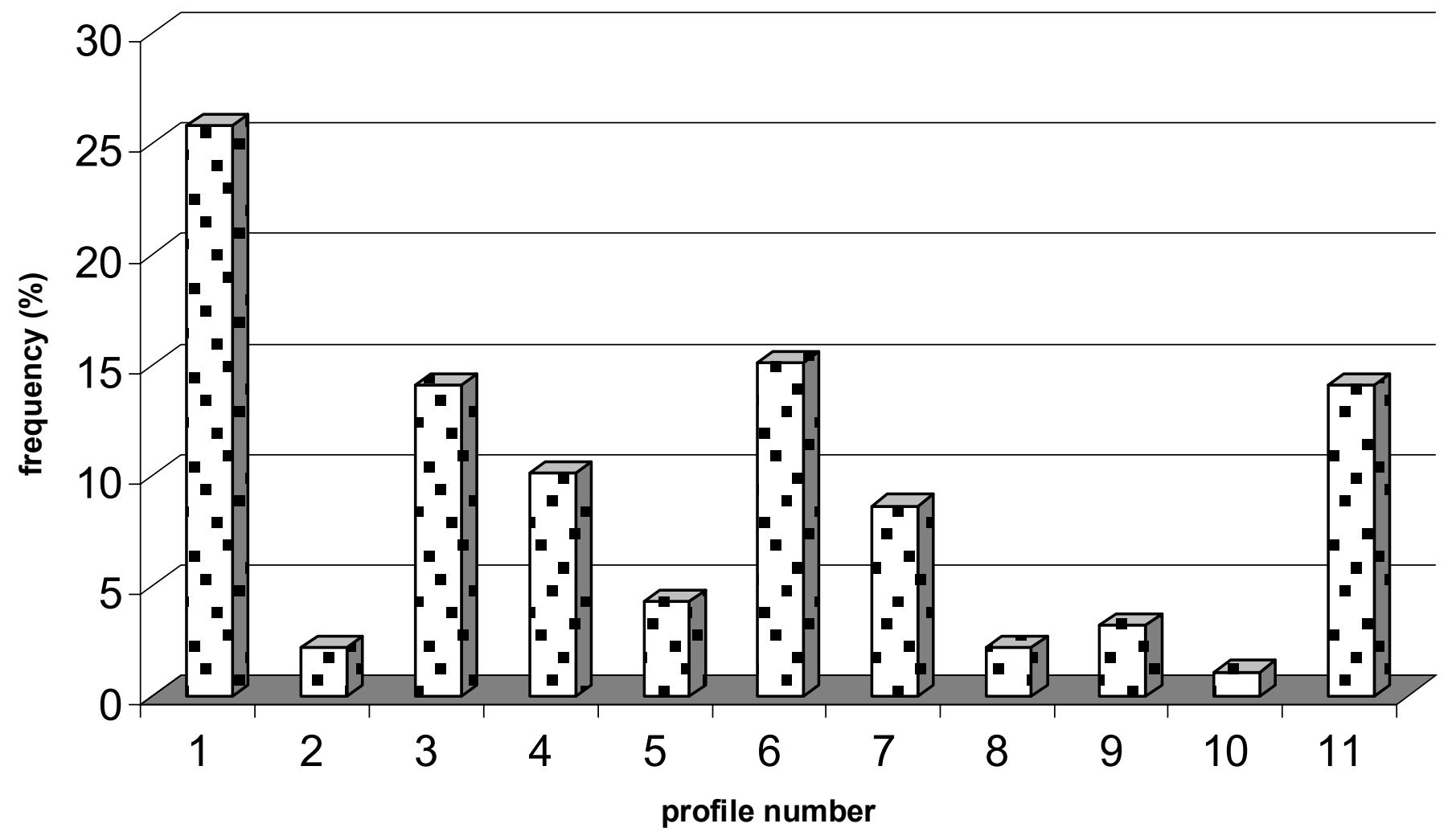

